\title{
Longitudinal study on steroid hormone variations during the second trimester of gestation: a useful tool to confirm adequate foetal development
}

Silvia Alonso ${ }^{1}$, Sara Caceres ${ }^{1 *}\left(\mathbb{D}\right.$, Daniel Vélez², Luis Sanz ${ }^{2}$, Gema Silvan ${ }^{1}$, Maria Jose Illera ${ }^{1}$ and Juan Carlos Illera ${ }^{1}$

\begin{abstract}
Background: The interaction of hormonal factors are crucial for good foetal development. During the second trimester of gestation, most of the main physiological processes of foetal development occur. Therefore, the aim of this study was to determine the variations in the physiological levels of cortisol, estriol, estrone sulphate, and progesterone during the second trimester (weeks 12-26) in order to establish normal ranges that can serve as indicators of foetal well-being and good functioning of the foetal-placental unit.

Methods: Saliva samples from 106 pregnant women were collected weekly (from week 12 to week 26 of gestation), and hormonal measurements were assayed by an enzyme immunoassay. The technique used for hormone measurements was highly sensitive and served as a non-invasive method for sample collection.

Results: The results revealed a statistically significant $(p<0.05)$ difference between cortisol, progesterone, and oestrogens throughout the second trimester, with a more substantial relationship between oestrogens and progesterone [P4-E3 ( $r=0.427) ; \mathrm{P} 4-\mathrm{E} 1 \mathrm{SO} 4(\mathrm{r}=0.419)]$. By analysing these hormone concentrations, statistically significant $(p<0.05)$ elevations in progesterone, cortisol, and estriol levels were found at the $16^{\text {th }}[(P 4(0.78 \pm 0.088)$, $C(1.99 \pm 0.116), E 3(2.513 \pm 0.114)]$; 18th [(P4 (1.116 \pm 0.144$), C(3.409 \pm 0.137), E 3(3.043 \pm 0.123)]$ and 23rd week of gestation $[(P 4(1.36 \pm 0.153), C(1.936 \pm 0.11), E 3(2.657 \pm 0.07)]$. Estrone sulphate levels appeared to increase progressively throughout the second trimester [from $1.103 \pm 0.03$ to $2.244 \pm 0.09$ ].

Conclusion: The 18th week of gestation seems to constitute a very important week during foetal adrenal development, and the analysis of the main hormones involved in foetal development, provided more precise information regarding the proper functioning of the foetal unit and foetal development.
\end{abstract}

Keywords: Cortisol, Estriol, Estrone sulphate, Progesterone, Pregnancy, Foetal development

* Correspondence: sacacere@ucm.es

'Departamento de Fisiología, Facultad de Veterinaria, Universidad Complutense de Madrid, 28040 Madrid, Spain

Full list of author information is available at the end of the article

C C The Author(s). 2021 Open Access This article is licensed under a Creative Commons Attribution 4.0 International License, which permits use, sharing, adaptation, distribution and reproduction in any medium or format, as long as you give appropriate credit to the original author(s) and the source, provide a link to the Creative Commons licence, and indicate if changes were made. The images or other third party material in this article are included in the article's Creative Commons licence, unless indicated otherwise in a credit line to the material. If material is not included in the article's Creative Commons licence and your intended use is not permitted by statutory regulation or exceeds the permitted use, you will need to obtain permission directly from the copyright holder. To view a copy of this licence, visit http://creativecommons.org/licenses/by/4.0/. The Creative Commons Public Domain Dedication waiver (http://creativecommons.org/publicdomain/zero/1.0/) applies to the data made available in this article, unless otherwise stated in a credit line to the data. 


\section{Background}

The physiological processes involved in pregnancy mainly depend on the interactions of hormonal factors, where the foetal-maternal endocrine system plays an important role. The placenta modulates the regulation of distinct factors by feedback mechanisms for correct foetal development [1]. The placenta and foetal adrenal gland are the organs responsible for producing large amounts of steroid hormones in the second and third trimester of gestation [2]. Progestogens, oestrogens, androgens, and glucocorticoids are secreted at different times during gestation, and their interactions modulate different cellular and physiological responses [1].

Most oestrogens are produced by the placenta and are sulphated or inactivated in the foetal liver to protect the foetus from excess oestrogen levels. Foetal exposure to abnormal concentrations of steroid hormones can have a negative impact on foetal development [3].

The main steroid hormones produced in the foetal adrenal glands are pregnenolone (P5), dehydroepiandrosterone (DHEA), and cortisol (C). P5 and DHEA act as substrates for the synthesis of progesterone (P4) and oestrogens in the placenta [2].

P4 and oestrogens are progressively secreted throughout gestation, and P4 levels are responsible for the maintenance of pregnancy [1]. Oestrogens, such as estriol (E3) and estrone sulphate (E1SO4), are produced by the placenta from dehydroepiandrosterone sulphate (DHEA$\mathrm{S})$, which is synthesised exclusively by the foetal adrenal glands [4]. E1SO4 acts as a reserve for the peripheral formation of bioactive estrogenic forms [5]. Likewise, E3 is the dominant oestrogen hormone during pregnancy and is used as an index of the state of the foetalplacental unit since its production depends on the synthesis capacity of the foetus and placenta together [4]. C levels are associated with the placental synthesis of crucial oestrogens for the maintenance of pregnancy, [5] playing an important role throughout pregnancy, and are responsible for maintaining intrauterine homeostasis.

Immunoassays of maternal blood samples are used for steroid concentration during pregnancy [6]. However, new methods using amniotic fluid samples, such as liquid chromatography-tandem mass spectrometry (LCMS/MS), have been given consideration since they are more reliable and sensitive [7]. In this study, we present the use of saliva samples for the determination of steroid hormone levels with immunoassay techniques as sensitive and non-invasive methods.

The knowledge of the interactions of the main steroid hormones during the second trimester of gestation is poor. Considering that significant foetal development events occur during the second trimester of pregnancy, [8] the aim of this study was to determine the levels of P4, E3, E1SO4, and C in saliva samples of pregnant women during the second trimester of pregnancy (from weeks 12-26) in order to evaluate hormonal variations and their interactions.

\section{Methods \\ Participant recruitment}

The study was carried out at the Nuevo Belén Clinical University Hospital (Madrid, Spain) in collaboration with the Department of Animal Physiology of the University Complutense of Madrid (Spain). The process of patient recruitment and sample collection were carried out for over a year (Sept 2017- Sept 2018). An informed consent was obtained from all participants recruited on this study.

A total of 161 healthy pregnant women without any pregnancy complications, aged between 27 and 44 years $(34.88 \pm 3.29)$ were recruited (data from all recruited woman are summarized in Table 1). Two of the initial participants dropped out before the beginning of the study, which made us commence with a total of 159 women, of whom they dropped out throughout the study reaching a total of 106 who completed the study. All women who fulfilled the inclusion criteria were included during the recruitment period. The criteria for inclusion were good overall health, age $>18$ years, no current systemic pharmacotherapy, and no smoking. They were also required to be in the second trimester. The exclusion criteria were the following: kidney disease, thyroid disease, autoimmune disease, cancer, pregestational diabetes, gestational diabetes, pregestational hypertension, overweight, obesity, in vitro fertilisation with heparin treatment, and current steroid treatment.

\section{Saliva sample collection and hormone measurements}

Saliva samples were collected weekly from eligible women during the second trimester of pregnancy (from weeks 12-26) with a Salivette collection tube. All samples were collected at an established time (10:00 am \pm 1 hour). The Salivette tube was centrifuged for $15 \mathrm{~min}$ at $2000 \times \mathrm{g}$ and $4^{\circ} \mathrm{C}$. The obtained saliva was stored at a temperature of $-20^{\circ} \mathrm{C}$ until further hormonal analysis.

P4 (ab: C914), E1SO4 (ab: R522-2), E3 (ab: 4835), and $\mathrm{C}$ (ab: R4866) concentrations were assayed by enzyme immunoassay (EIA). All hormone concentrations are expressed in $\mathrm{ng} / \mathrm{ml}$.

The validation technique parameters (recovery rates, sensitivity, intra- and inter-assay coefficients of variation, and parallelism) were assayed as previously reported by Illera et al., (2014) [9]. The EIA techniques and the antibodies used were developed and validated in the Endocrinology Laboratory of the Department of Animal Physiology (Faculty of Veterinary Medicine, Universidad Complutense de Madrid). 
Table 1 Data from all recruited women

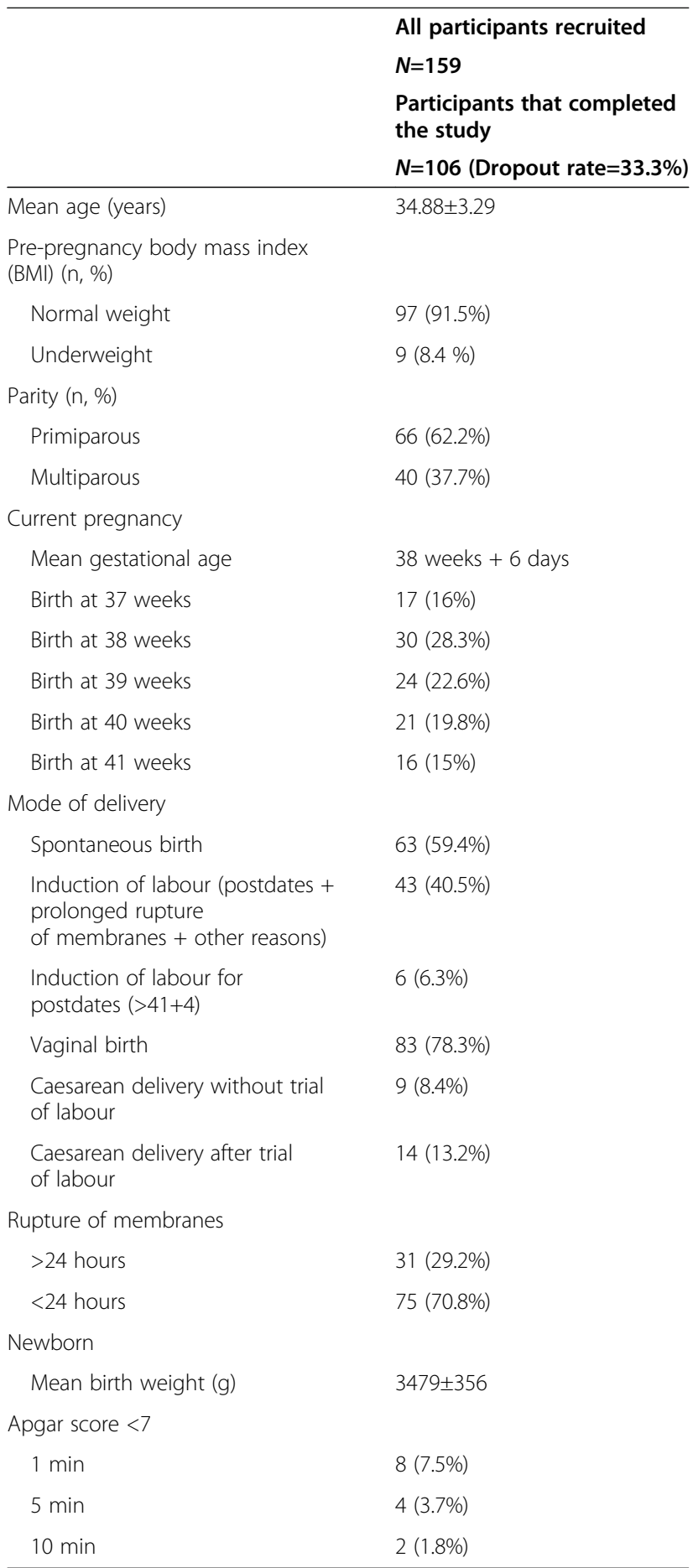

\section{Statistical analysis}

The hormonal concentration data were analysed with the SAS 9.4 program. Descriptive statistical analysis for mean and standard deviation of each hormone based on the week of delivery was performed, Repeated measures ANOVA was perfomed in order to compare the evolution of P4, E1SO4, E3, and C concentrations throughout the addressed experimental weeks. Repeated measures correlation coefficient (rmcorr) between hormonal values during the third trimester were estimated using PROC MIXED procedures by SAS.

Validation technique parameters (recovery rates, sensitivity, and intra- and inter-assay coefficients of variation) were calculated as previously described by Andreasson et al., 2015 [10]. Parallelism was calculated using ANOVA analysis [11]. Data are expressed as the mean \pm standard error. In all statistical comparisons, $p$-values of $p<0.05$ were considered statistically significant.

\section{Results}

\section{Clinical characteristics of the study group}

A total of 159 healthy pregnant women were recruited at the obstetric clinic and prospectively followed from week 12 of gestation to delivery (Table 1). Of those, 106 $(66,6 \%)$ completed the study. From all women who completed the study, the mean age of the mother was $34.88 \pm 3.29$ years. Most of the women had a prepregnancy normal weight $(91,5 \%)$ while $8.4 \%$ had a prepregnancy underweight. $62 \%$ of the women were primiparous and $37.7 \%$ were multiparous. The mean gestational age was $38 \pm 6$ weeks. The mean birth weight was $3479 \pm 356 \mathrm{~g}$.

\section{Validation parameters}

The sensitivity of the EIA technique was verified by a low limit of detection and was calculated in 10 consecutive assays. Results from low limit detection were: $\mathrm{P} 4=$ $12.81 \mathrm{pg} /$ well, $\mathrm{C}=2.48 \mathrm{pg} /$ well, E3 $=1.87 \mathrm{pg} /$ well and E1SO4 $=4.24 \mathrm{pg} /$ well. The assessment of the recovery rates of the conjugate gave the following results: P4, 0.9: 1; C, 1.3:1; E3, 1.2:1; and E1SO4, 1.2:1 moles. The recovery of the enzyme activity after conjugation was more than $85 \%$ in all cases. The precision of P4, C, E3, and E1SO4 EIAs was determined by calculating the intraand inter-assay coefficients of variation (CV\%). Results from CV\% were: P4 = Intra: $3.6 \pm 0.86 \%$, Inter: $5.2 \pm$ $0.91 \%$; $C=$ Intra: $4.9 \pm 0.92 \%$, Inter: $6.9 \pm 1.13 \%$; E3 = Intra: $7.1 \pm 1.16 \%$, Inter: $8.6 \pm 1.76 \%$; and E1SO4 = Intra: $7.8 \pm 1.14 \%$, Inter: $9.4 \pm 2.16 \%$. In order to determine the effects of saliva on the standard curve, the standard curves with saliva samples were run in parallel with the standard dose-response curve. Correlations between both standards curves resulted in a good degree of parallelism between both standard curves for the hormones studied $\left(\mathrm{P} 4, \mathrm{R}^{2}=0.86 ; \mathrm{C}, \mathrm{R}^{2}=0.84 ; \mathrm{E} 3, \mathrm{R}^{2}=0.89\right.$; and $\left.\mathrm{E} 1 \mathrm{SO} 4, \mathrm{R}^{2}=0.83\right)$.

\section{Hormonal concentrations}

A progressive increase in E1SO4 and E3 levels (Fig. 1a, b) was shown throughout the second trimester of gestation (weeks 12-26) (E1SO4: $1.104 \pm 0.032$ to $2.245 \pm$ 

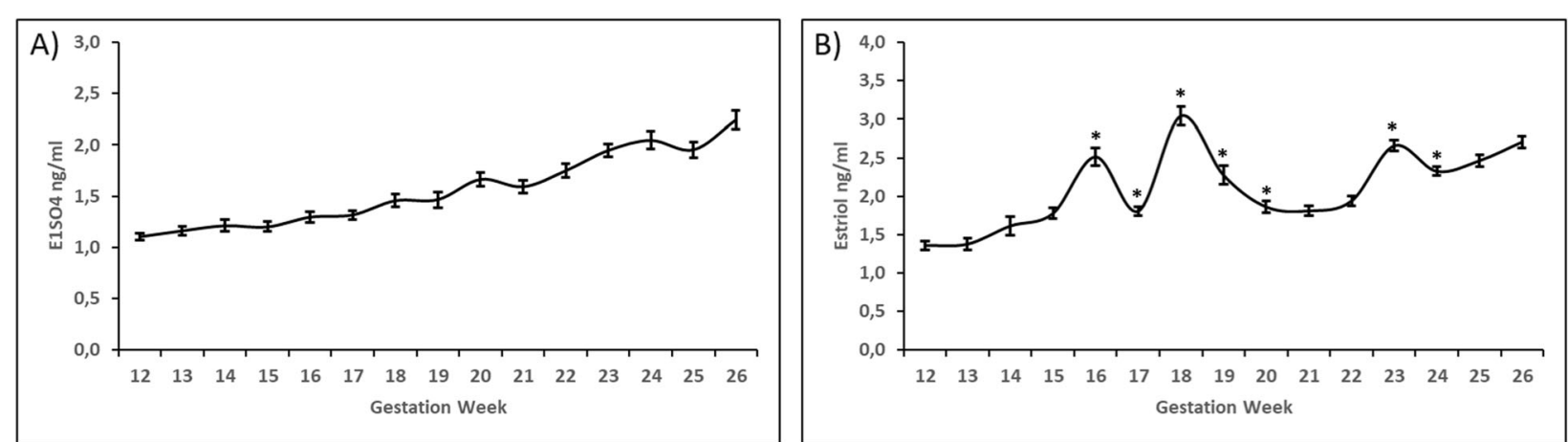

Fig. 1 Estrone sulphate $(\mathbf{a})$ and estriol (b) concentrations during second of pregnancy (12-26 weeks). Values are represented by means \pm SD. * denoted statistical significance throughout experimental weeks

0.093; E3: $1.358 \pm 0.059$ to $2.708 \pm 0.074)$. Increases in E3 levels $(p<0.05)$ were also found during the 16th, 18th, and 23rd weeks, with the greatest increase found during the 18 th week $(3.044 \pm 0.123)$.

The same progressive increase in P4 levels was found (Fig. 2a) during the second trimester $(0.456 \pm 0.014$ to $1.530 \pm 0.018$ ), and two clinically significant elevations in the 18th and 23rd weeks were found. Nevertheless, a slight increase in P4 levels was found in the 16th week, but there was not a statistically significant increase in E3 concentrations.

Although a progressive increase in $C$ levels during the weeks studied was not found (Fig. 2b), significant increases in $C$ levels were shown in the 16th, 18th, and 23rd weeks, with the greatest increase during the 18th week $(3.409 \pm 0.138)$.

Being rmcorr the correlation taking into account repeated measures, positive correlations were found between the hormones studied (Table 2), with stronger correlations between P4 and E3 (rmcorr $=0.407$ ) and P4 and E1SO4 ( $\mathrm{rmcorr}=0.443$ ) and lower correlations between $\mathrm{C}$ and E3 (rmcorr $=0.257$ ) and $\mathrm{C}$ and P4 $($ rmcorr $=0.147)$.

\section{Discussion}

Understanding of the interactions of hormonal factors displayed during the second trimester of gestation is crucial. It is difficult to directly compare these results with other previous studies due to the different methodologies used, such as hormonal measurements at specific moments during pregnancy (especially during the last weeks of pregnancy) or measurements using different biological samples. Some authors have suggested the need for longitudinal studies to explain the different types of prenatal stress and their relationship with maternal physiology and the outcomes of childbirth [12].

The main contribution of this study is that it shows the physiological variations of four of the main hormones involved during the second trimester of pregnancy (C, E3, $\mathrm{P} 4$, and E1SO4). However, more longitudinal studies of women during the second trimester are needed to address these findings. We also incorporated the analysis of these hormones in saliva samples, a non-invasive method for measure good-functioning of foetal-unit development. Also, the technique used in this study, developed by Illera et al., (2014) [9] was found to be highly sensitive and accurate. Therefore, we implemented the analysis of these
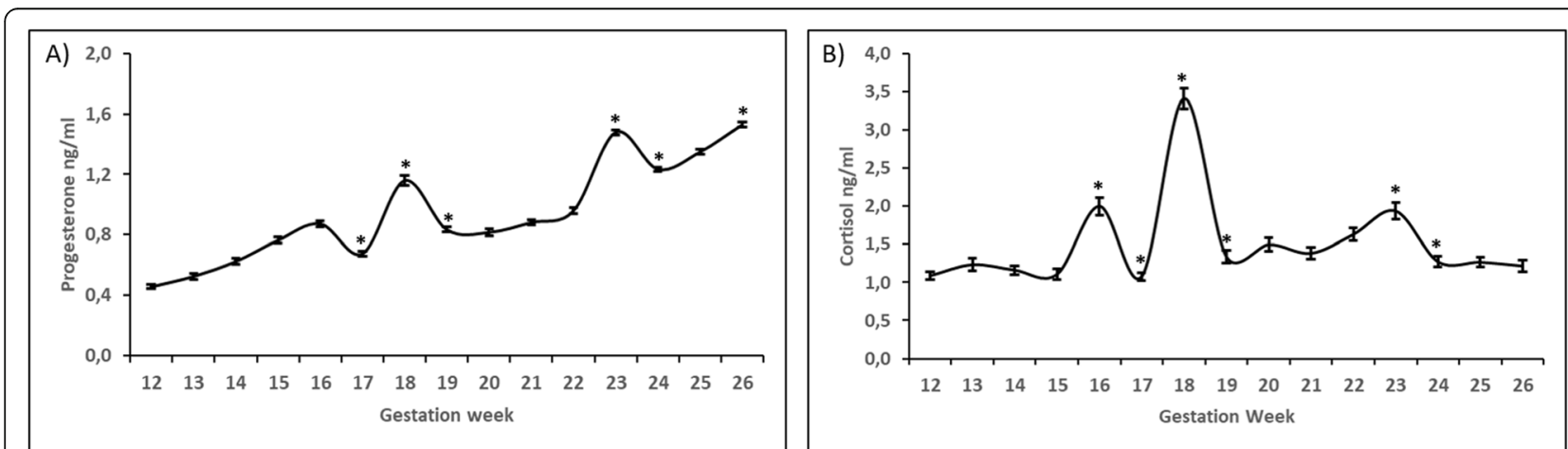

Fig. 2 Progesterone (a) and cortisol (b) concentrations during second of pregnancy (12-26 weeks). Values are represented by means \pm SD. * denoted statistical significance throughout experimental weeks 
Table 2 Repeated measures correlation (rmcorr) of P4, C, E3, and E1SO4 concentrations in the second trimester of gestation

\begin{tabular}{lll}
\hline From week $\mathbf{1 2}$ to $\mathbf{2 6}$ & & \\
\hline$v 1$ & $v 2$ & $\rho_{v 1 v 2}$ \\
\hline CORTISOL & ESTRIOL & 0.2570254 \\
CORTISOL & PROGEST & 0.30937017 \\
CORTISOL & E1SO4 & 0.0921688 \\
ESTRIOL & PROGEST & 0.407928 \\
ESTRIOL & E1SO4 & 0.14707268 \\
PROGESTE & E1SO4 & 0.44360565 \\
\hline
\end{tabular}

hormones in saliva samples, a useful non-invasive rising method where the collection of the sample does not cause stress and does not require training of health personnel.

Our results revealed that the four hormones analysed are positively correlated, with the most important correlation between oestrogens (E3 and E1SO4) and P4 in the second trimester of gestation. Indeed, greater increases in C, E3, and P4 levels were found in the 16th, 18th, and 23rd weeks of gestations.

Defining the exact moment during gestation in which the foetal adrenal cortex begins to function, as well as defining the mechanism by which it begins to function, is complex [13]. Howland et al. [14] suggested that the foetal HHA axis starts to function autonomously at around midgestation, reaching full development at 2 years of age. Nonetheless, some authors have stated that the foetal adrenal gland functions autonomously starting during the 8th week of gestation [2].

Based on our results, the increase in $\mathrm{C}$ found during the 18th week of gestation can be correlated with the autonomous function of the adrenal gland, which leads to higher secretion of $\mathrm{P} 4$ and higher oestrogen levels. However, other authors stated that the synthesis of de novo $\mathrm{C}$ begins in the definitive zone of the adrenal gland at week 23 of gestation [15].

It is known that the second trimester of pregnancy is the most sensitive to variations of maternal $\mathrm{C}$ concentrations could causing adverse effects on foetal development [16]. There is a controversy regarding $C$ levels and its association with stress. Several studies correlated C levels with maternal stress, [17] whereas other authors suggested that $C$ variations are affected by biological factors rather than lifestyle factors as stress $[18,19]$. In accordance with these authors, our results did not revealed any association with $C$ levels and maternal stress.

$\mathrm{C}$ levels has been also associated with birth weight [18] or even children weight (2 to 16 years old) [16]. As some authors determine that higher $\mathrm{C}$ levels during pregnancy may be a risk factor for low birth weight, [18] other authors suggested that higher $\mathrm{C}$ levels are associated with children overweight [16].
Some authors revealed that the combined effect of high levels of estradiol and P4 affected to the production of coagulation factor and, therefore, develop a prothrombotic state during first trimester of pregnancy [20]. However, the increased in E3 and P4 levels in this study cannot be correlated with this phenomenon, as all pregnant women did not have any complications during pregnancy.

Foetal movements are considered a sign of maturity of the neurological system and of the well-being of the foetus [21]. A mother's perception of these movements begins between weeks 16 and 20 of pregnancy [22]. As early as week 24 , the foetus is capable to integrate the exteroceptive and interoceptive stimuli, such as feelings, memories, and emotions, [23, 24] being able at this stage to integrate external sensory information and to develop a physiological and behavioural response [24]. At week 16 , the foetus is also able to move in a coordinated manner. These movements can be perceived by the mother and detected by ultrasound techniques, [24] and the increase in the intensity of these movements have been associated with higher $C$ levels, [25] which can be related with the increase in $C$ levels found at 16th week.

It is also during these weeks that the development of the sensorimotor capacity of the foetus begins. At around week 16, the foetus develop spontaneous motor activity during active sleep, [26] and nociceptive reactions can be recorded starting at week 20 [27]. At around 22-23 week fetus develop the capacity to detect and memorize the consequences of spontaneous activity as arm movements towards mouth and eyelids [26].

The strengths of our study included the comparison of the four hormones simultaneously during the same gestational period and their analysis in saliva. However, several limitation has been noted. Firstly, it was the participant recruitment as well as the significant drop-out rate. Secondly, another limitation found was the lack of continuity in the weekly collection of samples by the participants due to forgetfulness.

Despite the positive correlations found between the courses of different hormone levels, it can't be said firmly whether these positive correlations are due to interactions of the hormones studied or whether they independently rise over time. However, knowing the hormonal variations throughout the second trimester of pregnancy could serve as an indicator of proper functioning of the adrenal axis, leading to normal foetal development.

\section{Conclusions}

The knowledge and analysis of the factors that influence foetal development and their possible consequences can help to improve the preventative measures provided by health professionals during pregnancy. 
The increase in C, P4, and E3 levels at the 18th week of gestation can be related to the autonomous function of the foetal adrenal gland, suggesting that is a key week for foetal development. Although saliva based diagnostics still require further investigation for its implementation as analytical method, the analysis of the $\mathrm{C}$, P4, and oestrogen concentrations in saliva samples during the second trimester of pregnancy (specifically at 18 th week), is a non-invasive and low-cost technique that can be a very useful tool to confirm the favourable development and functioning of the foetal endocrine system.

The results obtained in this exploratory study contribute to the generation of new hypotheses regarding the study of the development in the second trimester of gestation.

\section{Abbreviations}

C: Cortisol; E3: Estriol; E1SO4: Estrone sulphate; EIA: Enzyme immunoassay; P4: Progesterone; Rmcorr: Repeated measures correlation coefficient

\section{Acknowledgements}

The authors are thankful to the data collectors, supervisors, and participants for their involvement and time.

\section{Authors' contributions}

All authors have read and approved the manuscript. S.A: Design of study, acquisition, analysis and interpretation of data. Article drafting and revising. S.C: Design of study, acquisition, analysis and interpretation of data. Article drafting and revising. D.V: Analysis and interpretation of data. Article drafting and revising. L.S: Analysis and interpretation of data. Article drafting and revising. G.S: Design of study, acquisition, analysis and interpretation of data. Article drafting and revising. MJ. I: Design of study, acquisition, analysis and interpretation of data. Article drafting and revising. JC. I: Design of study, acquisition, analysis and interpretation of data. Article drafting and revising.

\section{Funding}

Not applicable.

\section{Availability of data and materials}

The datasets generated and/or analysed during the current study are not publicly available due to the women who participated in the study did not agree to use their individual data in the signed consent document for participation in the research, but are available from the corresponding author on reasonable request.

\section{Ethics approval and consent to participate}

This study has been approved by the Clinical Research Ethics Committee of HM Hospitals, with the code CEIm HM hospitals: 16.06.0960-GHM, in accordance with the World Medical Association and the Declaration of Helsinki. All participants signed consent prior to participation and were allowed to stop participation without prejudice. Reporting of the study conforms to broad EQUATOR longitudinal studies guidelines [28].

\section{Consent for publication}

Not applicable.

\section{Competing interests}

The authors declare that they have no competing interests.

\section{Author details}

'Departamento de Fisiología, Facultad de Veterinaria, Universidad Complutense de Madrid, 28040 Madrid, Spain. ${ }^{2}$ Department of Statistics and Operational Research, Faculty of Mathematics, University Complutense of Madrid, 28040 Madrid, Spain.
Received: 19 June 2020 Accepted: 3 February 2021

Published online: 09 February 2021

\section{References}

1. Morel Y, Roucher F, Plotton I, Goursaud C, Tardy V, Mallet D. Evolution of steroids during pregnancy: Maternal, placental and fetal synthesis. Annales D’Endocrinologie. 2016;77:82-9.

2. Johnston ZC, Bellingham M, Filis P, Soffientini U, Hough D, Battacharya MS, et al. The human fetal adrenal produces cortisol but not detectable aldosterone throughout the second trimester. BMC Med. 2018;16:23.

3. Miranda A, Sousa N. Maternal hormonal milieu influence on fetal brain development. Brain Behav. 2018;8:e00920.

4. Falah N, Torday J, Quinney SK, Hass DM. Estriol review clinical application and potential biomedical importance. Clin Res Trials. 2015;1:29-33.

5. Geyer J, Bakhaus K, Bernhardt R, Blaschka C, Dezhkam Y, Fietz D, et al. The role of sulfated steroid hormones in reproductive processes. J Steroid Biochem Mol Biol. 2017;172:207-21.

6. Pasqualini JR, Chetrite GS. The formation and transformation of hormones in maternal, placental and fetal compartments: biological implications. Horm Mol Biol Clin Investig. 2016;27(1):11-28.

7. Fahlbusch FB, Heussner K, Schmid M, Schild R, Ruebner M. Measurement of amniotic fluid steroids of midgestation via LC-MS/MS. J Steroid Biochem Mol Biol. 2015;152:155-60.

8. Deter RL, Lee W, Kingdom J, Romero R. Second trimester growth velocities: assessment of fetal growth potential in SGA singletons. J Matern Fetal Neonatal Med. 2019:32(6):939-46.

9. Illera JC, Silvan G, Cáceres S, Carbonell MD, Martínez-Fernández L, Munro C, Casares M. Assessment of ovarian cycles in the African elephant (Loxodonta africana) by measurement of salivary progesterone metabolites. Zoo Biol. 2014;33(3):245-9.

10. Andreasson U, Perret-Liaudet A, van Waalwijk Doorn, LJC, Blennow K, Chiasserini D, Engelborghs, et al. A practical guide to immunoassay method validation. Front Neurol. 2015:6:179.

11. Carlsson MO, Zou KH, Yu CR, Liu K, Sun FW. A comparison of nonparametric and parametric methods to adjust for baseline measures. Contemp Clin Trials. 2014;37:225-33.

12. Walsh K, McCormack CA, Webster R, Pinto A, Lee S, Feng T, Krakovsky S, et al. Maternal prenatal stress phenotypes associate with fetal neurodevelopment and birth outcomes. PNAS. 2019;116(48):23996-4005.

13. Xing $Y$, Lerario AM, Rainey W, Hammer GD. Development of adrenal cortex zonation. Endocrinol Metab Clin North Am. 2015;44(2):243-74.

14. Howland MA, Sandman CA, Glynn LM. Developmental origins of the human hypothalamic-pituitary-adrenal axis. Expert Rev Endocrinol Metab. 2017; 12(5):312-39.

15. Narasaka T, Suzuki T, Moriya T, Sasano H. Temporal and spatial distribution of corticosteroidogenic enzymes immunoreactivity in developing human adrenal. Mol Cell Endocrinol. 2001;174:111-20.

16. Hohwü L, Henriksen TB, Grønborg TK, Hedegaard M, Sørensen TLA, Obel C. Maternal salivary cortisol levels during pregnancy are positively associated with overweight children. Psychoneuroendocrinol. 2015;83:143-52.

17. Shelton MM, Schminkey DL, Groer MW. Relationships among prenatal depression, plasma cortisol, and inflammatory cytokines. Biol Res Nurs. 2014. 17(3):295-302.

18. Bolten MI, Wurmser H, Buske-Kirschbaum A, Papoušek M, Pirke KM, Hellhammer D. Cortisol levels in pregnancy as a psychobiological predictor for birth weight. Arch Womens Ment Health. 2011;14:33-41.

19. Bleker LS, Roseboom TJ, Vrijkotte TG, Reynolds RM, de Rooij SR. Determinants of cortisol during pregnancy - The ABCD cohort. Psychoneuroendocrinol. 2017:83:172-81.

20. Bagot CN, Leishman E, Onyiaodike CC, Jordan F, Gibson VB, Freeman DJ. Changes in laboratory markers of thrombotic risk early in the first trimester of pregnancy may be linked to an increase in estradiol and progesterone. Thromb Res. 2019:178:47-53.

21. Gran-Beuttler M, Glynn LM, Salisbury AL, Davis EP, Holliday C, Sandman CA. Development of fetal movement between 26 and 36-weeks gestation in response to vibro-acoustic stimulation. Front Psychol. 2017;2:350.

22. Akkaya H, Büke B. A frequently asked question: Is it normal not to feel my baby movements yet? J Chin Mec Assoc. 2018;81:742-6.

23. Torres Martí JM, Melero López A, Lopez Gonzalez MA. Consideraciones generales y concepto de edad perinatal. El feto en los distintos meses del embarazo. Tratado de ginecología y obstetricia. $2^{\text {a }}$ ed. Editorial médica 
paramericana; 2015. https:/www.edicapanamericana.com.bucm.idm.oclc. org/visorebookv2/ebook/9788498357516.

24. Moore KL. Periodo fetal: desde la novena semana hasta el nacimiento. Embriología clínica. 10a ed. Elsevier España. 2016. https://www-clinica Ikey-com.bucm.idm.oclc.org/student/content/book/3-s2.0-B978849022 9873000060.

25. Di Pietro J, Kivlighan KT, Laudenslager ML, Costigan KA. Fetal motor activity and maternal cortisol. Dev Psychobiol. 2009;51:505-12.

26. Fagard J, Esseily R, Jacquey L, O'Regan K, Somogyi E. Fetal origin of sensorimotor behavior. Front Neurorobot. 2018;12:23.

27. Bellieni C. New insights into fetal pain. Semin Fetal Neonatal Med. 2019; 24(4):101100.

28. Von Elm E, Altman DG, Egger M, Pocock SJ, Gotzsche PC, Vandenbroucke JP. The strengthening the reporting of observational studies in epidemiology (STROBE) statement: guidelines for reporting observational studies. J Clin Epidemiol. 2008;61(4):344-9.

\section{Publisher's Note}

Springer Nature remains neutral with regard to jurisdictional claims in published maps and institutional affiliations.

Ready to submit your research? Choose BMC and benefit from:

- fast, convenient online submission

- thorough peer review by experienced researchers in your field

- rapid publication on acceptance

- support for research data, including large and complex data types

- gold Open Access which fosters wider collaboration and increased citations

- maximum visibility for your research: over $100 \mathrm{M}$ website views per year

At BMC, research is always in progress.

Learn more biomedcentral.com/submissions 